\title{
Serosal Surface of the Liver
}

National Cancer Institute

\section{Source}

National Cancer Institute. Serosal Surface of the Liver. NCI Thesaurus. Code C33538.

The membrane lining the external surface of the liver. 